\section{Development of the tilted vertical horopter}

\section{S. KREKLING and S. BLIKA University of Trondheim, Trondheim, Norway}

Binocular space along the vertical meridian of the visual field is disparity biased since the locus of points seen in corresponding visual directions by the left and the right eye is represented by a single line tilted in the median plane with its top away from the observer (e.g., Tyler \& Scott, 1979). This tilt means that the uniocular images of the so-called vertical horopter (Amigo, 1974) are slightly rotated in opposite directions about the visual axes. The angular difference in orientation between the two images of the vertical horopter is an expression for the orientationdisparity bias of the binocular system.

Several lines of psychophysical evidence (e.g., Ames, 1926; Cogan, 1979; Emsley, 1939; Helmholtz, 1867; Trendelenburg, 1961; Tyler, 1980; Volkmann, 1863-1864) indicate that the orientation-disparity bias in normal adult human observers is about 2 deg, and is always equivalent to a horopter tilted with its top away from the observer. Helmholtz (1867) assumed that the orientation disparity of the vertical horopter, or shearing angle between corresponding "vertical meridians" (Tyler \& Scott, 1979), was equal to the arctan of the ratio between interpupillary distance (2a) and the observer's eye-to-ground distance (h). Furthermore, Helmholtz suggested that this disparity bias in binocular correspondence was a result of visual experience, representing an ontogenetic adaptation to the most frequently occurring disparity during habitual viewing of contours below eye level (ground, floor). A similar suggestion was made by Breitmeyer, Battaglia, and Bridge (1977). Consequently, it might be expected that the orientationdisparity bias of a more or less horizontal visual habitat would be roughly equal to $\arctan (2 \mathrm{a} / \mathrm{h})$.

This can be illustrated in the following way. When an observer looks at the ground at some intermediate distance (Figure 1), texture elements located closer than the fixation point give rise to crossed disparities, whereas elements farther than the fixation point produce uncrossed disparities. Progressively closer stimuli produce increasingly greater crossed disparities, whereas stimuli progressively farther away produce increasingly greater uncrossed disparities, with the uncrossed and crossed distribution in the upper and the lower visual hemifield, respectively. Consider elements located along the line at which the median

This work was supported by the Norwegian Research Council for Science and the Humanities. Requests for reprints may be addressed to S. Blika, Department of Ophthalmology, University of Trondheim, N-7000 Trondheim, Norway.

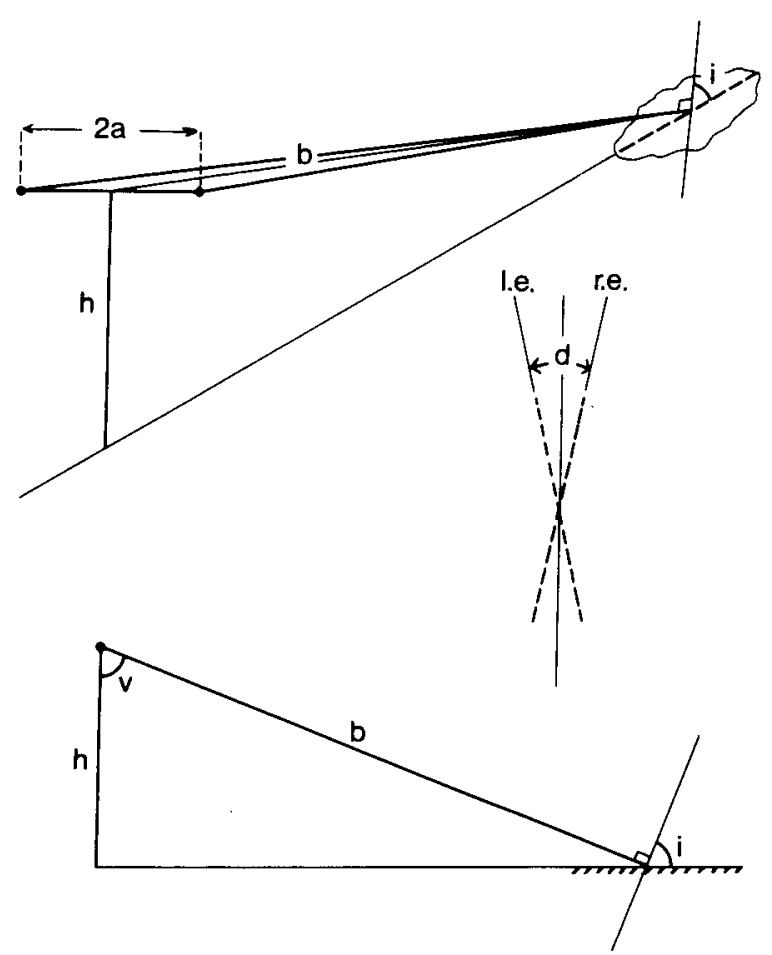

Figure 1. Stimulus elements along the intersection between the observer's median plane and the ground are indicated by the stippled line (upper drawing), the inclination (i) of which depends on observation distance (b) and eye-to-ground distance (h) since tan $i=$ $\left(b^{2}-h^{2}\right)^{3 / 2} / h$ (lower drawing). During binocular viewing, the disparity distribution produced by such stimulus elements may be expressed in terms of the orientation disparity (d) between the images in the left (l.e.) and right (r.e.) eye.

plane of the observer intersects with the ground. The projections of the line connecting these points on a plane orthogonal to the visual axes intersect at an angle $d$. The horizontal distance between the projections above and below the fixation point shows the horizontal disparity for elements located along the imaginary line on the ground, with uncrossed disparities above and crossed disparities below the point of fixation. This gradient of crossed and uncrossed disparities may conveniently be expressed in terms of orientation disparity (Bishop, 1978). According to Ogle (1964), the orientation disparity (d) of the line can be expressed as a function of observation distance (b), interpupillary distance (2a), and the inclination (i) between the ground and the orthogonal plane by the approximation $d=\arctan (2 a \tan i / b)$. Since angle $v$ is equal to $i, \tan i=\left(b^{2}-h^{2}\right)^{1 / 2} / h$, where $h$ is the height of the observer's eyes above the ground. Richards (1975) suggested that the eye-to-ground distance might conveniently serve as a unit for radial spatial distances. Observation distance may therefore 
be expressed as multiples of $h$; i.e., $b=n h$, and accordingly, tand $=2 a\left(n^{2}-1\right)^{1 / 2} / n h$. For intermediateto-far observation distances, $\left(n^{2}-1\right)^{1 / 2}$ becomes approximately equal to $n$ and, accordingly, $d=\arctan$ $(2 \mathrm{a} / \mathrm{h})$.

Helmholtz (1867) compared the orientation disparity values of near vertical corresponding meridians obtained by psychophysical measurements with calculated disparity values obtained from data on interpupillary distance and eye-to-ground distance for three observers. The average difference between calculated and measured values was about $0.10 \mathrm{deg}$, suggesting that the orientation disparity bias of the vertical horopter was rather closely matched to a corresponding stimulus bias in the visual habitat. To what extent this relationship applies to the average adult human observer is not well known, however. Van Moll (1874) obtained data on 20 subjects and found that the angular tilt of the vertical horopter in several observers was quite different from that estimated on the basis of the ratio between interocular and eye-to-ground distance. On the other hand, neurophysiological data on normally reared cats and burrowing owls (terrestrial) indicate that the orientation disparity bias of binocular vertical meridians actually corresponds to arctan of this ratio (Cooper \& Pettigrew, 1979). Furthermore, it has recently been shown that exposure to an orientationdisparity-biased surrounding tends to modify binocular properties of striate neurons. Bruce, Isley, and Shinkman (1981) and Hanny and von der Heydt (1982) exposed kittens to an artificially orientationdisparity-biased visual input and found a systematic exposure-dependent shift in the mode of the orientation-disparity scatter of receptive fields in binocular neurons. Since the mode of the disparity scatter presumably represents the neural substratum of the horopter (Bishop, 1973), these findings indicate that the vertical horopter tilt can be modified to match the most frequently occurring aspects of binocular visual exposure during development.

It is not very likely, however, that the vertical horopter tilt in adult human observers is the result of an ontogenetic adaptation to a more or less constant orientation-disparity bias of binocular visual input, because the growth of interpupillary distance and body height may not be strictly correlated. This is illustrated in Figure 2. The curve (A) showing growth of interpupillary distance was based on the mean of two sets of measurements (Garrigosa \& Isisarri, 1968; Lucas \& Pryor, 1935), and the curve (B) showing growth of body height (stature) represents the mean for three subjects (Guttmann, 1915). Although the growth curves for interpupillary distance ( $2 a)$ and body height (H) follow approximately the same course during development, the ratio between the two measures is not constant. The resulting orientation-disparity bias was estimated from $\arctan (2 a / H)$, and Figure $2 C$ shows
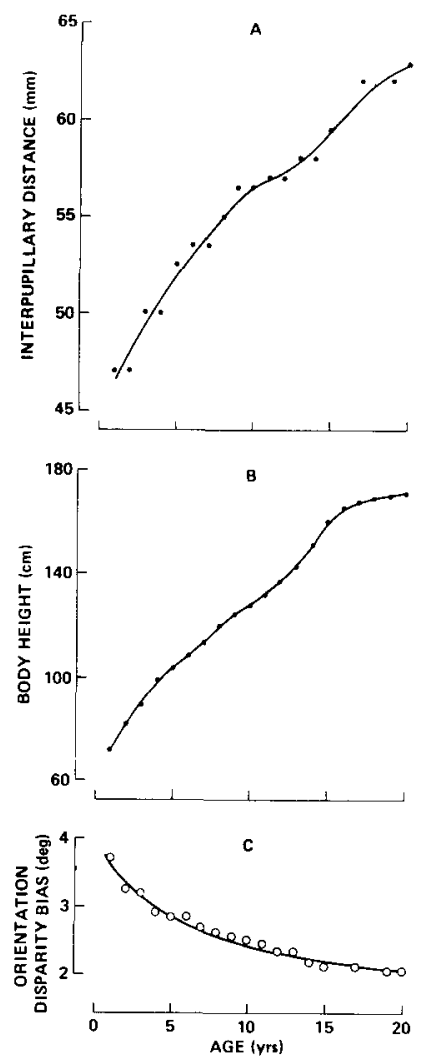

Figure 2. The curve (A) showing growth of interpupillary distance was based on data published by Garrigosa and Irisarri (1968) and Lucas and Pryor (1935), and the curve (B) showing growth of body height was based on data from Guttmann (1915). The curve in (C) showing orientation disparity bias as a function of age was obtained by calculating arctan to the ratio between interpupillary distance and body height.

that disparity bias (ordinate) declines gradually from birth towards a constant value during the mid teenage years. The calculated values probably represent an underestimate of the true disparity bias, since body height is somewhat larger than eye-to-ground distance. Nevertheless, the curve (Figure 2C) indicates that visual orientation-disparity bias is not constant, but declines as a function of age. Since the shearing angle between corresponding binocular meridians, or mode of the disparity scatter of binocular neurons, tends to match the disparity bias of visual input (Bruce et al., 1981; Hänny \& von der Heydt, 1982), this implies that the tilt of the vertical horopter also is variable and would reach adult value after a period of continuous adaptation to a gradually changing, age-dependent disparity bias in visual input.

No direct evidence is available to support this suggestion, but clinical data on patients with early onset of cyclotropia (Guyton \& von Noorden, 1978) indicate that orientation-disparity properties of binocular correspondence are modifiable in humans, too. Furthermore, data on the susceptibility to abnormal 
binocular experience (Banks, Aslin, \& Letson, 1975) indicate that binocular connectivity in the human visual cortex retains some plasticity up to at least 6-8 years of age. The idea that the vertical horopter tilt in man represents an ontogenetic adaptation to an ecological tilt therefore remains an attractive hypothesis.

\section{REFERENCES}

Ames, A. Cyclophoria. American Journal of Physiological Optics, 1926, 7, 3-38.

Amigo, G. A vertical horopter. Optica Acta, 1974, 21, 272-292.

Banks, M. S., Aslin, R. N., \& Letson, R. D. Sensitive period for the development of human binocular vision. Science, 1975, 190, 675-677.

Bishop, P. O. Neurophysiology of binocular single vision and stereopsis. In R. Jung (Ed.), Handbook of sensory physiology (Vol. VII/3). New York: Springer-Verlag, 1973.

Bishop, P. O. Orientation and position disparities in stereopsis. In S. J. Cool \& E. L. Smith (Eds.), Frontiers in visual science. New York: Springer-Verlag, 1978.

Breitmeyer, B., Battaglia, F., \& Bridge, J. Existence and implications of a tilted binocular disparity space. Perception, 1977, 6, 161-164.

Bruce, C. J., Isley, M. R., \& Shinkman, P. G. Visual experience and development of interocular orientation disparity in visual cortex. Journal of Neurophysiology, 1981, 46, 215-228.

Cogan, A. I. The relationship between the apparent vertical and the vertical horopter. Vision Research, 1979, 19, 655-665.

Coopra, M. L., \& Petrigrew, J. D. A neurophysiological determination of the vertical horopter in the cat and owl. Journal of Comparative Neurology, 1979, 184, 1-26.
Emsley, H. Visual optics. London: Hatton Press, 1939.

Garrigosa, C., \& Irisarri, J. P. La distancia interpupilar y las distancias de centros des las monturas. Archivos de la Sociedad oftalmologica hispano-americana, 1968, 28, 541-561.

GuttmanN, M. Einige Beispiele individueller körperlichen Entwicklung. Zeitschrift für Kinderheilkunde, 1915, 13, 248-256.

GuYton, D. L., \& von Noorden, G. K. Sensory adaptation to cyclodeviations. In R. D. Reinecke (Ed.), Strabismus. New York: Grune \& Stratton, 1978.

HÄNNY, P., \& von DER HEYDT, R. The effect of horizontal-plane environment on the development of binocular receptive fields of cells in cat visual cortex. Journal of Neurophysiology, 1982, 329, 75-92.

Helmholtz, H. Handbuch der physiologischen Optik. Leipzig: Voss, 1867.

Lucas, W. P., \& Pryor, H. B. Range and standard deviations of certain physical measurements in healthy children. Journal of Pediatrics, 1935, 6, 533-545.

Oale, K. N. Binocular vision. New York: Hafner, 1964.

Richards, W. Visual space perception. In E. C. Carterette \& M. P. Friedman (Eds.), Handbook of perception (Vol. 5). New York: Academic Press, 1975.

Trendelenburg, W. Der Gesichtssinn. Berlin: Springer-Verlag, 1961.

TYLen, C. W. Binocular moiré fringes and the vertical horopter. Perception, 1980, 9, 475-478.

Tyler, C. W., \& Scotr, A. B. Binocular vision. In R. E. Records (Ed.), Physiology of the human eye and visual system. Hagerstown, Md: Harper \& Row, 1979.

VAN Mout, F. D. A. C. Over de normale incongruentie der netviezen. Utrecht: Broese, 1874.

Volxmann, A. W. Physiologische Untersuchungen im Gebiete der Optik. Leipzig: Breitkopf \& Härtel, 1863-64.

(Manuscript received August 1, 1983; accepted for publication August 17, 1983.) 